\title{
Literatura de viagens e outras deslocaçôes: deam- bulações reflexivas
}

Fátima Outeirinho

Univ. Porto - ILC

Resumo: Partindo da revista Granta, trata-se de atentar num feixe de questões que parecem acompanhar, de modo constante, o itinerário da literatura de viagens num quadro transnacional, procurando contribuir para voltar a lembrar, no espaço da academia, questões e desafios que se erguem neste campo quer no plano da produção, quer no plano da receção.

Palavras-chave: Literatura de viagens, escrita de viagens, Granta

Abstract: Taking as a starting point the Granta magazine, we aim to address a set of subjects that seem to constantly follow the itinerary of travel literature in a transnational framework, seeking to contribute to remembering, within the academy space, issues and challenges that arise in this field and at the level production and reception.

Keywords: Travel literature, travel writing, Granta

Is travel writing dead? Tal é a pergunta que, em 2017, a edição inglesa da revista Granta coloca a diferentes autores, no seu número de inverno intitulado Journeys. Para além das respetivas respostas, o número integra, igualmente, textos vários em torno de deslocações. Observe-se, en passant, que Granta. The magazine of new writing tem acolhido em diferentes momentos do seu percurso não apenas textos esparsos ligados às viagens, mas também números temáticos especificamente votados a uma escrita de viagens, como sucede a partir da década de 80: Travel writing em 
1983, Travel em 1989 (em homenagem a Bruce Chatwin), Necessary journeys de 2001, On the road again: where travel writing went next de 2006, Travel de 2013 e, mais recentemente, Journeys.

Não pretendo desenvolver neste espaço uma recensão crítica da revista, mas tão só atentar num feixe de questões que parecem acompanhar, de modo constante, o itinerário da literatura de viagens num quadro transnacional, ocidental é certo, e que talvez importe lembrar. Partir de Journeys serve este propósito, pois esta edição reúne um conjunto de textos-depoimento, de jornalistas-escritores, poetas e romancistas contemporâneos, merecedores de atenção pelas pistas de reflexão para que apontam quando se trata de pensar o binómio literatura e viagem que está na base da constituição de um corpus comummente identificado como literatura de viagens. Aquilo de que estes depoimentos são também reveladores afinal é, em alguns casos, uma visão estereotipada e preconceituosa, menorizadora de toda uma produção textual que tenderia a cultivar apenas uma dimensão hedonista, lúdica e, com frequência, etnocentrada.

Talvez uma primeira observação desde logo se imponha: o reconhecimento de uma oscilação terminológica, tantas vezes de funcionamento sinonímico não sustentado e sobre a qual já muitos se atardaram, como por exemplo Carl Thompson na sua obra crítica de 20Iı. Com efeito, tal oscilação emerge de modo iterativo nestes textos ancorados linguisticamente na anglofonia: escrita de viagens, literatura de viagens são etiquetas usadas sem grande reflexão e que podem identificar objetos textuais, com frequência bem diversos, suportados por meios de difusão também singulares e nem sempre de função, objetivos e contexto equivalentes. Como mais adiante veremos, esta vagueza terminológica levará também a incluir diferentes e novas declinações de um fazer literário assente na viagem que, com mais propriedade, poderiam caber sob a designação de literatura de migração ou literatura de exílio, ou ser alvo de abordagens tematológicas, já que nesta relação de viagem e literatura muitas vezes está em causa a exploração do entendimento do ser humano enquanto homo viator ou, como dirá na revista Moshin Hanmid, "the movement through time is our shared journey” (2017: 155), neste sentido defendendo que toda a escrita é escrita de viagens (idem).

Atentemos, em seguida, no texto de introdução de Sigrid Rausing e que se revela interessante pela inscrição que faz de toda uma produção textual assente na viagem. Afirma Rausing: "Granta has long been associated with this particular form of creative-non-fiction." E de imediato acrescenta: "It was sometimes more creative than readers and editors knew" (idem: 10), lembrando o caso de Kapuscinski ou de Chatwin, e trazendo para a discussão a questão da delimitação categorial de todo um acervo textual polimorfo, ou o vaivém entre facto e ficção, ou até uma dimensão ética dessa mesma produção. Com efeito, observa ainda Rausing: 
And sticking to the truth, of course, is not the whole story. Travel writing is about place, but it is also usually, one way or another, about people, the inhabitants of those places to which the author travels. These people are, by definition, different from the author, and can be exoticised, objectified or mocked in any number of ways. But I still think that writing about other people doesn't have to be an exercise of power or a theft of identity. It can be done with engagement, empathy and respect. (ibidem)

A conceção de literatura de viagens que aqui aflora não causa surpresa; ela passa pela habitual identificação de um objeto que trabalha o encontro entre culturas, reconhece a existência de uma produção de difícil ou definitiva categorização e caracterização, pois trata-se, na verdade, de uma por vezes só aparente não-ficção criativa. No que toca ao impacto que a narrativa de viagens pode ter no plano da receção, a reserva e mesmo críticas que, nomeadamente numa etapa pós-colonial, emergem, face a uma literatura de marcas imperiais ou neocoloniais e que colocam em destaque apenas esta dimensão, de algum modo não deixam de ser lembradas por Rausing. O legado, transformado muitas vezes num fantasma, de uma literatura de viagens eurocêntrica que o expansionismo europeu fez emergir, continua presente e a assombrar o século XXI, gerando reservas e preconceitos, desde logo políticos, como já lembrava Tim Youngs em "The importance of travel writing” (2004), e dentro do espaço da academia. Tal identificação da literatura de viagens com esse percurso histórico e seus prolongamentos, ainda nos dias de hoje, pode também ser encontrado junto dos criadores contemporâneos. Lembremos tão somente o testemunho de lan Jack nesta mesma revista: "travel writing of the most kinds (...) has the history of colonialism perched on its shoulder" (2017: 91). Mesmo se um outro autor, Rana Dasgupta, positivando uma ação e presenças ocidentais, escreve em etapa liminar, "What is travel writing? A testament to the heroic of the Western spirit: its readiness to dance and drink with the remotest beings, its ability to human tragedy.// Once upon a time this meant something. (2017: 158), o escritor não deixa de sublinhar o carácter anacrónico de uma tal atuação no presente. Outros ainda lembram as relações, talvez pouco claras, entre turismo e literatura de viagens, lembrando uma produção textual que se aproxima do pacote turístico e que pode inscrever-se em duas categorias: a viagem nos passos de... e a viagem de..., em que o carácter eventualmente inusitado do meio de transporte seria um dos focos de atenção (Dyer 2017: 156).

Face a este contexto, percebe-se mais claramente o porquê de Sigrid Rausing, no seu editorial, ter o cuidado de marcar a existência de outros caminhos ou a importância de os trilhar através de "engagement, empathy, respect", revelando porventura a necessidade de defender a honorabilidade e pertinência deste objeto literário. E se exemplos precisássemos de que a literatura de viagens não se tem limitado a testemunhar um encontro de culturas ou a fazer perceber que esse encontro com o outro é inevitavelmente um encontro com o eu, mas pode também encerrar uma dimensão 
de engagement - não necessariamente à la Sartre -, mas um comprometimento revelador de uma consciência de pertença à humanidade e que resultará numa preocupação ética, encontrá-los-íamos em textos tão diversos como A Baía dos Tigres de Pedro Rosa Mendes ou Sibéria de Olivier Rolin.

A leitura posterior dos diferentes depoimentos permite-nos identificar então este e outros eixos, possibilitando uma reflexão quer sobre aquilo que a caracterizará por si mesma e / ou dentro do fazer literário em geral, quer sobre o passado, presente e mesmo futuro da escrita de viagens, ou ainda sobre os desafios que um género resiliente e variado enfrenta, nas palavras do escritor Colin Thubron (2017: 95), numa era globalizada e digital: uma crescente cultura partilhada, uma circulação e acessibilidade da informação que resultaria na rarefação do desconhecido e, por consequência, na impossibilidade de a literatura de viagens continuar a cumprir aquele que foi visto durante tanto tempo como o seu ou um dos seus principais papéis, o alargamento de saberes sobre o Outro culturalmente distinto - esquecendo afinal que informação não é exatamente o mesmo que conhecimento -, uma diversidade de contextos mediáticos, com consequências para a própria construção narrativa, e de que são exemplos Afonso Cruz com Jalan Jalan (no que toca a uma similitude com o funcionamento hipertextual próprio da web) ou Afonso Reis Cabral em Leva-me contigo, explorando um pré-contacto com a receção ao ir dando conta da viagem em curso, numa rede social como o Facebook, para depois integrar na publicação em livro posts deixados no mural, nomeadamente por recetores que são igualmente produtores.

No que toca a uma caracterização definidora de travel writing, lan Jack regressa a uma definição dada também na revista Granta da década de 80: “pre-eminently a narrative told in the first person, authenticated by lived experience", em que "the narrative usually finds its focus in a journey" (2017: 90). Samanth Subramanian, por sua vez, sublinha o facto de que a literatura de viagens não pode ser vista apenas, ou apenas valorizada, no que respeita à possibilidade de dizer o espaço, de o dar a conhecer. Se fosse essa a sua função maior seria nos nossos dias algo de supérfluo e tal entendimento reduziria a literatura de viagens a um quadro só utilitário. Subramanian lembra então que literatura de viagens é experiência do espaço e experiência do tempo, num tempo dado, e sublinha: "The literature of travel describes the world as it is - but only as it is in its instant, as it appears to the particular sensibility of the passing witness" (2017: 6I). E a testemunha é, convém lembrá-lo, alguém que se situa numa esfera de criação. Está-se assim perante propostas singulares de representação, modos de fazer mundos que se ancoram voluntaria e explicitamente numa dimensão vivencial, pessoal a marcar genologicamente as narrativas de viagem.

Alexis Wright, escritora australiana, pertencendo ao povo Waanyi, coloca o enfoque no leitor e nos novos caminhos que uma escrita de viagens deverá percorrer: como leitora, recorda a viagem pela imaginação que tais escritos lhe proporcionaram e lembra ainda que viajar na cultura do outro potencia a viagem na sua própria cultu- 
ra (Wright 2017: 93). A reflexão de Alexis Wright dá conta porém de um novo foco de atenção e preocupação com consequências para a escrita de viagens: se alguns falam do seu próprio lugar, no mundo de hoje muitos existem sem lugar a que chamar seu (ibidem). Para Wright, um imperativo ético ergue-se e que tem de ser considerado: acolher a voz dos que buscam asilo, contribuir para que ela seja ouvida (idem: 94), transformando assim a nossa imaginação.

Também Rana Dasgupta ou Lindsey Hilsum defenderão o virar para uma nova página neste domínio, apontando para novas dinâmicas de deslocação ligadas a migrações e exílios. Diz, por exemplo, Hilsum:

We need a new genre of travel writing, gleaned from the stories refugees and migrants tell housing officials, charity centres, immigration officers, health workers and school administration staff. Not everything said or written would be true - exaggeration and elision have long been hallmarks of travel writing. Maybe a new style could escape the brureaucratic language to which these dramatic journeys are usually reduced. (2017:59)

As narrativas destes seres em deslocação são para ela "the travellers' tales that define our times" (ibidem). Um último aspeto com interesse para a reflexão e que alguns destes escritores referem passa pelo entendimento de que mais do que falar de escrita de viagens ou literatura de viagens importa falar de literatura; e um destes escritores, Geoff Duyer, chega mesmo a dizer que a pergunta a colocar - caso houvesse cabimento - seria a de se a literatura morreu, afirmação provocatória, mas significativa pela valorização e reconhecimento a cultivar face a uma produção textual por vezes esquecida ou menos prestigiada e prestigiante em termos de criação literária.

Esta deambulação pela revista Granta e por um conjunto de considerações reflexivas de autores vários e bastante diversos em termos de percurso biográfico (idade, inscrição no espaço cultural, atividade profissional), ou em termos de percurso criativo, serve-me não tanto para avançar com respostas definitivas, que as não há, mas sobretudo - assim o espero - para contribuir para relembrar, no espaço da academia, questões e desafios que se erguem neste campo quer no plano da produção, quer no plano da receção. Trata-se, de novo, de tomar consciência do lugar indecidível que esta produção textual ocupa pelo facto de habitar a fronteira, e desde logo em termos genológicos, por ser marcada por processos de liminaridade e, por esse motivo, disponível para acolher a mudança, a criatividade, as redescrições do fazer literário, sempre em constante metamorfose. Assim, se algo definitivo pode ser afirmado é, como já dizia lan Jack, “Travel writing isn'tdead. It just isn't what it was” (2017:92). E sem querer assumir um falso e dispensável papel de adivinho, apresar de tudo acrescentarei: It won't be what it is now. Mas esta expectativa é também o que nos move como leitores e seduz na literatura de viagens. 


\section{Bibliografia}

Cabral, Afonso Reis (2019), Leva-me contigo, Alfragide, D. Quixote.

Cruz, Afonso (2017), Jalan Jalan, Lisboa, Companhia das Letras.

(1983), Granta. The magazine of new writing. Travel writing, 10.

(1989), Granta. The magazine of new writing.Travel, 26.

(2001), Granta. The magazine of new writing. Necessary journeys, 73.

(2006), Granta. The magazine of new writing. On the road again: where travel writing went next, 94.

(2013), Granta. The magazine of new writing.Travel, 124.

(2017), Granta. The magazine of new writing. Journeys, 138.

(2017) "Is travel writing dead?", Granta. The magazine of new writing. Journeys, 138, pp. 58-60; 90-102; 153-159; 177-179; 182-183; 222.

Mendes, Pedro Rosa (2013), A Baía dos Tigres, Alfragide, D. Quixote.

Rausing, Sigrid (2017), "Introduction”, Granta. The magazine of new writing. Journeys, 138, pp. IO-II.

Rolin, Olivier (2016), Sibéria. Lisboa, Tinta da China.

Thompson, Carl (2011), Travel Writing, New York, Routledge.

Youngs, Tim (2004), "The importance of travel writing”, The European English Messenger, 13.2, pp. 55-62. 